\title{
A constituição da formação de professores em processos de iniciação à docência
}

\section{The constitution of teacher education in initiation to teaching processes}

DOI: 10.54019/sesv2n1-001

Recebimento dos originais: 07/01/2021

Aceitação para publicação: 29/01/2021

\begin{abstract}
Alan Gonçalves Lacerda
Doutor em Educação em Ciências e Matemática pela UFMT, Brasil

Instituição: Universidade Federal do Pará - Campus Marajó - Breves

Endereço: Av. Gurupá, 1480, Aeroporto-Breves -PA

E-mail:lacerda.a.g@gmail.com
\end{abstract}

\section{RESUMO}

Este artigo tem como objetivo analisar o contexto de formação de jovens futuros professores de matemática em processo de iniciação à docência, no que tange os sentidos atribuídos à experiência com o uso da tecnologia por um aluno bolsista, que se dá na relação entre teoria e prática, contextualizadas no âmbito do Programa Institucional de Iniciação à Docência (PIBID). Para o desenvolvimento desse estudo problematizamos: Quais os desafios à inicialização da prática docente em matemática, focado na comunicação matemática? Dentre outros resultados, destacamos que 0 professor iniciante se constitui numa relação conflituosa entre a formação especifica e pedagógica. Pontuamos ainda, a formação inicial a exigência e a necessidade de um novo perfil de aluno-professor, que nos leva a pensar na formação educacional com a tecnologia e as atividades colaborativas. Tais ambientes educacionais com o uso de tecnologia e prática colaborativa, exigem sem dúvida, a repensar uma nova postura e ações ao enfrentamento da inicialização à docência.

Palavras-chave: Formação de professores. PIBID. Educação Matemática.

\section{ABSTRACT}

This article aims to analyze the context of training of young future teachers of mathematics in the process of initiation to teaching, regarding the meanings attributed to the experience with the use of technology by a student stock market, which occurs in the relationship between theory and practice, contextualized in the scope of the Institutional Program of Initiation to Teaching. For the development of this study, we discuss: What are the challenges to the initiation of teaching practice in mathematics, focused on mathematical communication? Among other results, we emphasize that the beginning teacher is a conflicting relationship between specific and pedagogical training. We also point out the initial formation of the requirement and the need for a new student-teacher profile, which leads us to think about educational formation with technology and collaborative activities. Such educational environments with the use of technology and collaborative practice, 
undoubtedly require rethinking a new attitude and actions to confront initialization to teaching.

Keywords: Teacher training. PIBID. Mathematical Education.

\section{INTRODUÇÃO}

A discussão sobre a relação universidade, escola e formação de professores é um tema recorrente na atualidade e, da qual vem ganhando destaque principalmente, por políticas de desenvolvimento e aprimoramento de ações para Educação Básica, estimulados por programadas de incentivo e valorização do magistério. Nesse âmbito, nasce o Programa Institucional de Bolsas de Iniciação à Docência (PIBID). Tais discussões trazem em seu bojo a relação conflituosa entre a teoria e a prática, a formação específica e a formação pedagógica, e propõem ainda o estreitamento das relações universidade e escola.

Tomando como recorrência as discussões, tais como as polêmicas: Quando o aluno em formação inicial se propõe a refletir sobre o conhecimento matemático e pedagógico? Quais estratégias podem orientar a prática docente de professores em fase de iniciação à docência? Como percebemos, essas perguntas permeiam outras: em que consiste o exercício docente na atualidade? Quais os desafios na implementação de atividades para as aulas da Educação Básica, sobretudo na incorporação dos elementos da pesquisa? Objetivando explicitar a partir das ações engajadas por um dos alunos integrantes do PIBID que fez uso do software GeoGebra: Quais os sentidos atribuídos a experiência com o uso da tecnologia? Quais os desafios à inicialização da prática docente em matemática, focado na comunicação matemática?

"Diante da complexidade das relações comunicacionais no mundo contemporâneo, os educadores escolares precisam aprender a pensar e a praticar comunicações midiatizadas" (LIBÂNEO, 2011, p. 71). Entendendo assim, as mídias representam implicações didáticos- pedagógicas, que cada vez mais se desenvolvem sob uma leitura crítica e reflexiva. Vendo as dificuldades dos professores em acompanhar as Tecnologias da Informação e Comunicação nas aulas de matemática é preciso práticas específicas e formas de trabalho que envolve equipes integradas, experienciadas com/na aproximação do futuro professor à realidade escolar. 
Se recorremos a literatura em educação e educação matemática, podemos identificar uma série de autores, que teorizam sobre as profissões e o processo de profissionalização, sendo escasso os estudos que abordem a prática docente colaborativa e os desafios profissionais, principalmente, aqueles que iniciam o exercício do magistério. Como veremos no tocante a alguns pontos teóricos analisados, esse será o traço dado nas secções subsequentes desse artigo.

Responder às perguntas apresentadas no início dessa seção, exige e necessita de um novo perfil de sujeito, que nos leva a pensar na formação educacional com a tecnologia. Tais ambientes educacionais com o uso de tecnologia, exigem sem dúvida, a repensar uma nova postura e relações dos seres humanos com mídias. Nestas perspectivas, que se delineia o artigo, ao trazer os sentidos da experiência realizada por um dos bolsistas do PIBID ao utilizar o software GeoGebra para aprendizagem de conceitos matemáticos para alunos da Educação Básica.

2 O PROGRAMA INSTITUCIONAL DE BOLSAS DE INICIAÇÃO À DOCÊNCIA: PERSONAGENS, CAMINHOS E FORMAÇÃO

O projeto PIBID/Matemática/Breves teve início com o edital 061/2013. Os projetos vinculados ao PIBID/UFPA visam à inserção dos futuros professores e a contribuir na formação inicial dos alunos participantes e do professor supervisor.

O PIBID é um Programa de incentivo docente, valorização do magistério e de aprimoramento das estratégias didático-pedagógicas. O programa oferece bolsas a alunos da graduação, supervisor e coordenador. Com o apoio financeiro da CAPES, o Programa Institucional de Bolsa de Iniciação à Docência (PIBID/2013) vem sendo desenvolvido na Universidade Federal do Pará que tem como eixo central proporcionar uma formação inicial de qualidade. O estudante de licenciatura é o principal personagem do PIBID, pois o programa se destina a enriquecer suas vivências e estratégias pedagógicas. Elevar a qualidade da formação inicial é um dos focos desse programa.

Diante dessa perspectiva de trabalhar com os alunos da graduação, e, sobretudo, com a possibilidade de elaborar e executar coletivamente uma prática que se representa uma experiência de formação inicial dos licenciandos em matemática é que os nossos encontros passaram a ser realizados. 
Assim, nos encontros, os participantes envolvidos refletiam sobre as atividades dialogadas sugeridas pelo coordenador, e passaram a pesquisar sobre os temas sugeridos: Qual o papel do Geogebra no desenvolvimento de conceitos matemáticos? Nessas perspectivas, tal contexto de partida era o compromisso educativo com um trabalho pedagógico, com o intuito de não situar as heranças obsoletas, ligadas às imagens de instrutor, domesticação da pedagogia do professor (DEMO, 2011).

Nesse mesmo contexto, cabe analisar também a criticidade de tratamento do conteúdo nos moldes predeterminados que pontuem a transmissão do conhecimento. Um desafio crucial não é apenas a profissionalização do acadêmico, mas igualmente, em recuperar suas precariedades trazidas da trajetória escolar (DEMO, 2011). Afirma Nóvoa, (1992, p. 27) "é preciso investir positivamente os saberes de que o professor é portador, trabalhando-os de um ponto de vista teórico e conceptual".

Para Fiorentini, Souza e Melo (2003, p. 311), a relação que acadêmicos e professores mantêm com os saberes é que faz toda a diferença, "relação essa que, na maioria das vezes, é decorrente de uma cultura profissional marcada pela racionalidade técnica que supervaloriza o conhecimento teórico". Cabem aqui algumas reflexões sobre o caráter aberto da metodologia para fins teóricos e práticos. Deste modo, paralelamente à leitura de trabalhos de Libâneo (2011) entendo que a teoria deve recai na prática como atividade formadora.

Desse modo, a um aspecto importante na consideração desse grupo de trabalho, que diz respeito a participação dos jovens participantes nas dinâmicas estabelecidas numa trama comunicacional de práticas para sala de aula. Para Libâneo (2011) é preciso potencializar a aprendizagem pelas competências do pensar, e, portanto, traduzem-se em objetos de ações a realizar e reagir a elas. John Dewey explica, na obra Como Pensamos (2010) a emergência do ato de pensar como ação emancipatória das atividades meramente rotineiras e impulsivas.

Disto isto, um dos fatores responsáveis pelos resultados da conotação putativa educacional está associado a hábitos de leituras de cunho técnico no ensino, por envolver mais o lado da motivação a expressar-se com instrumentação. Neste sentido, vale ressaltar que a formação inicial exige sem 
dúvida a repensar uma nova postura e ações ao enfrentamento da inicialização à docência. Como regra, a matemática não dispensa cuidados com procedimentos, passos, técnica, o que a leva a reconhecer que em cada estilo há diferenças, está apenas em acentuar concepções e abordagens variando necessariamente à prática.

Assim, há diferentes aspectos envolvidos na formação, onde os alunos devem ser convidados, da qual a atividade não pode ser compulsória, mas constituída como um processo aberto. Tais funções pressupõem a pessoa que age, o que combinaria com a aprendizagem como ação (ALRO; SKOVSMOSE, 2006).

As funções acima mencionadas pertencem claramente às tarefas, cujos problemas situam a cooperação investigativa, da qual os autores Alro e Skovsmose (2006), a veem como parte essencial do desenvolvimento de comunicação e aprendizagem da matemática. Há assim aspectos importantes da prática pedagógica que tem como base o ensino exploratório. Nestes tempos atuais de implementações de práticas pedagógicas de orientações para os professores que ensinam matemática, a uma orientação de estudos de Pontes (2017) e colaboradores por meio da discussão na aula de Matemática como aspecto da prática do professor.

Para Demo (2009, p. 34) "onde o professor apenas ensina, reproduz-se a sucata, não projeto próprio do desenvolvimento". Tentaremos a seguir discutir em nossos resultados situações-problemas do cotidiano, dos fenômenos reais; em outras palavras, procura-se introduzir à educação elementos que a situem na aprendizagem como ação.

Na verdade, o momento de inicialização a prática por alunos em formação inicial, no contexto do PIBID, recolhe uma atenção investigativa as pesquisas sobre prática colaborativas. Sendo assim, Menezes e Ponte (2009) sublinham a importância da colaboração por emergir de um trabalho de construção aos anseios de professores, com percursos diversos que se empenham num trabalho comum.

O trabalho de Menezes e Ponte ao investigar (2009) a prática de três professores do ensino básico de escolas portuguesas, procurou pontuar como se desenvolvem esses profissionais no contexto de um projeto de investigação 
colaborativa. Esses autores trouxeram como problemática: Como se desenvolvem profissionalmente professores do $1^{\circ}$ ciclo e $3^{\circ}$ ciclo, nas dimensões reflexão, conhecimento e práticas, colaboração e autonomia, no contexto de um projeto de investigação de natureza colaborativa, focado na comunicação matemática? 0 estudo de natureza qualitativa, procedeu aos instrumentos, tais como: diários dos professores, registro das atividades com auxílio de gravador e de notas de campo. Os resultados apontaram uma melhora nas práticas colaborativas, nas dimensões do conhecimento didático e na prática de aulas, principalmente no foco da comunicação nas aulas de matemática. Pois os professores se reconheceram como parte integrante e cooperativo, num trabalho de ajuda mútua frente aos desafios da profissão, sobretudo, suscitados pelas trocas de experiências, leituras e reflexões.

Consideramos, segundo Perez (2005, p.253), o papel das práticas colaborativas no seio de desenvolvimento de competências e saberes profissionais com o intuito de melhorar as instituições educativas.

3 Método, ações e escolhas: uma relação conflituosa a inicialização da prática docente

Procuramos assim, desenvolver ideias e práticas que possam expressar, da melhor forma possível, a escolha no âmbito do projeto do PIBID. Para fins de tratamento mais organizado, neste processo particular da pesquisa, faz-se necessário, a descrição das reuniões em que as tarefas foram constituídas diante da complexidade de informações.

A situação em que as informações foram geradas pude perceber, nas reações dos participantes, alguns problemas para a compreensão da relação didática e pedagógica. Já nessa primeira organização, faço um breve relato a partir do projeto que delimitam em cada situação e que me possibilitou a analisar as reuniões do grupo de trabalho.

As reuniões eram sempre aos sábados, além dos dez alunos de graduação contávamos ainda com a participação de um professor da rede municipal de ensino do município de Breves. Objetivamos com essas reuniões contribuir com processos teóricos e práticos de formação, esclarecendo que os alunos vinculados ao projeto iriam mobilizar os conhecimentos matemáticos nas escolas 
da educação básica, especificamente, nas turmas do professor/supervisor do projeto.

Nos encontros solicitei que desenvolvessem tarefas específicas de estudos, levando-se em consideração habilidades e competências, bem como, a adequação e a pertinência com o conteúdo e a carga horária da atividade proposta. As etapas foram sendo atualizadas por meio de leituras, onde os alunos em formação inicial procuravam informações através das mídias eletrônicas, em livros e/ou artigos, para posteriormente, desenvolverem suas aplicações e suas implicações para o ensino e aprendizagem das atividades propostas.

As pesquisas sobre os conteúdos específicos da matemática foram enriquecidas com o uso dos materiais didáticos e das metodologias no processo de orientação e convivência motivadora com os alunos da iniciação à docência. As pesquisas sobre os temas propostos avançaram radicalmente nas formas da compreensão do processo de ensino e aprendizagem, graças à tentativa de ampliar os significados da matemática, o que contribuiu para o conhecimento dos processos didático-pedagógicos.

Contudo, essa preparação do estudante gerou uma expectativa dos participantes com a ênfase nos métodos, instituída sempre no caráter mais marcante que é a instrução. Isso me levou a pensar "os porquês" de não termos atingido a qualidade educacional escolar, nas suas limitações e do seu potencial de ação. Isso me levou a consideração que no âmbito do Programa de Iniciação à docência poderíamos explorar a adoção de uma pesquisa de intervenção com o intuito de oportunizar as relativas mudanças na produção do conhecimento. Essa nova produção de análises possibilitou melhorar a demarcação de novas estratégias sobre o pensar/fazer na Educação Matemática.

Desse modo, a um aspecto importante na consideração veiculada com a produção educacional que é preciso garantir ao espaço escolar práticas e estudos sobre a pesquisa de desenvolvimento de recursos didáticos, e não como mero registro de algo acabado. Queremos, por fim, enfatizar o desafio estimulante que é a pesquisa de desenvolvimento que é a legitima preocupação manifestada professores como meios educativos para organização didática e prática de ensino. 
A par disso, deve-se ressaltar a importância da organização e planejamento das tarefas, e postar-se diante disso, o desafio como sujeito aprendente, e, não como repassador de conhecimento.

Nas reuniões incluía também a capacidade de se expressar, de tomar inciativa, de se fazer sempre participativo. Destacaríamos ainda um momento de levantar as motivações como organização de feiras de matemática, tomados como instigadores da capacidade do processo formativo.

As tarefas matemáticas têm uma dupla finalidade, alimentar o processo de argumentar e cultivar o aprender, que permite conjugar teoria e prática. Mais que isto, para privilegiar a instrumentação necessária, para garantir o bom desempenho e o aprimoramento da qualidade. Os lócus das pesquisas foram duas escolas públicas e o campus universitário do Marajó-Breves.

Nas escolas públicas foram desenvolvidas as tarefas pelos alunos de iniciação à docência e no campus universitário do Marajó/Breves iniciaram as reuniões para organização das atividades que, posteriormente, seriam realizadas nas escolas públicas do município de Breves. Nos encontros no campus Universitário eram esclarecidos os objetivos e intenção de realizar atividades que poderiam vir a ser ocorridas com o grupo de formadores, subdivididos em grupos menores. No decorrer das manifestações do grupo foi relatado as dificuldades que os alunos teriam em realizar o trabalho, sobretudo, na realização da filmagem. Diante do fato, consegui realizar algumas filmagens, e quando percebia 0 desconforto diante da filmadora desliguei e com o intuito de deixá-lo mais à vontade.

Esta análise deslocou minha atenção para o grupo de formadores, tomando por base quais as práticas leitoras e comunicativas em que os alunos em processo de formação inicial em matemática realizariam em suas tarefas. Para essa finalidade, privilegiamos as ações de elaborar tarefas com o intuito de propor reflexões, de construção de uma prática de iniciação à docência.

Assim, lidamos com a constituição do grupo com os desafios de implementação da atividade, objetivando explicitar a partir das ações engajadas no PIBID, quais as características que constituem a formação inicial em matemática? 
Nessa perspectiva, os contextos de desenvolvimento, no âmbito da pesquisa, constituíram como ponto de partida para repensar a formação didáticopedagógica. Esses pressupostos passam a se constituir também minhas atenções, bem como induzir a um conjunto de tarefas em que os alunos pudessem se envolver e desempenhar um papel ativo.

A pesquisa na formação é uma forma de mostrar, para os futuros professores, como é importante buscar novos conhecimentos, pois é preciso ser inovador, bem como ser criativo. Para tanto, consideramos no âmbito da elaboração da tarefa do professor um trabalho interativo e colaborativo. Por entender que os alunos em iniciação à docência é mais que um ser em processo de formação, mais um ser atuante e cooperativo, protagonista de suas tarefas.

Menezes e Ponte (2009) ao analisar a natureza das relações colaborativas dos professores, salientam três padrões de colaboração: ajuda e apoio, partilha e co-propriedade.

Ajuda e apoio "traduziu-se num relacionamento em que existiu uma clara assimetria na participação dos professores" (p.15). Observado apenas no professor participante mais jovem, que buscava respostas acabas e conclusivas as práticas letivas.

Partilha "assumiu-se como uma forma de colaboração que estava a meio caminho entre modos de trabalho de natureza individual e outros modos que envolviam maior compromisso e dispêndio de tempo" (p.17). Essas características se estenderam a dois professores nas mais deferentes formas de partilha de tarefas, de livros, de artigos e filmes.

Co-propriedade "de modo diferente da partilha, implicou maior compromisso de cada um com o grupo, através da divisão de tarefas e da procura de metas comuns para as quais todos contribuíram" (p.17-18).

Por seu lado, o programa de investigação colaborativa desenvolvido por Menezes e Pontes (2009) inclui sugestões para realização de projetos para prática profissional docente. E reconhecido no âmbito de nosso estudo como um papel potencializador para o processo de ensino e aprendizagem em matemática. Nessa mesma linha, que exponho as considerações sobre o projeto "A Pesquisa em Educação Matemática na formação de professores: metodologias e perspectivas para o Marajó/Breves" para elaboração desse artigo. Dessa forma, 
traça-se como objetivo principal desse trabalho o levantamento de experiências, contextualizadas no âmbito do PIBID, focado na comunicação matemática.

Sugerimos, assim, que a pesquisa do saber da ação pedagógica possa contribuir para o aperfeiçoamento da prática profissional docente. Em nossas análises explicitamos a importância da pesquisa colaborativa em processo de formação inicial e dos profissionais docentes, construindo assim, seu significado a partir de experiências com a formação.

Para isso, serão construídas aulas expositivas, dialogadas/relacionadas com os grupos de formação colaborativa, a qual serve de apoio ao professor para entender como os conteúdos foram planejados e construídos. Nas etapas relacionadas à construção das tarefas, irá ocorrer seleção e organização das atividades em grupos. Entendo, que o professor de matemática apropriando-se de recursos didáticos como o lúdico e o criativo, contribui com sua atuação e saber específicos. Nessa direção, encontramos pesquisas denominadas de colaborativa, realizadas na relação entre pesquisadores-professores da universidade e professores-pesquisadores nas escolas, utilizando como metodologia a pesquisa qualitativa.

Na reflexão crítica e conjunta, os sujeitos participantes são provocados a problematizar suas ações e as práticas pedagógicas, e a elaborar as tarefas a serem executadas no campo. É, pois, difícil estar de acordo sobre quais variáveis metodológicas nas quais se inserem a pesquisa, no entanto, filiar-se num movimento plural e diversificado de instrumentos de investigação. Como membro do grupo, e assumindo a responsabilidade de envolver os alunos nos quais a pedagogia tem uma história e assume um significado importante para 0 engajamento da tarefa investigativa.

Nesta visão bastante ambiciosa, o trabalho de pesquisa envolveu métodos e procedimentos variados. É por esta razão que situo mais claramente as observações, entrevistas, portfólios, notas de campo e episódios de ensino.

As observações se mostram como um importante recurso ao pesquisador no momento do registro relativo à prática da sala de aula, e recorreu-se a ela para entender melhor os fenômenos observados gestos, sinais corporais, falas e ações. Na pesquisa de campo, observei, no ato de ler nas aulas, a pergunta de investigação: o que se percebe naquele que lê e o que poderia se inferir no que 
ele faz? Decorre desse fato, qual o papel da comunicação nas práticas dos jovens/futuros professores de matemática? Quais interações mediadas pelas leituras nas ações do projeto PIBID? Quais vivências são características atributivas ao ensino e à aprendizagem de conceitos matemáticos?

Para elaboração da entrevista, considerei minha vivência com a temática investigada, bem como as formulações e orientações dadas pela literatura sobre os estudos que investigam a leitura e a comunicação. Conforme Duarte (2002, p.146), "aprender a realizar entrevistas é algo que depende fundamentalmente da experiência no campo". Assim, procedi às formulações das quatro perguntas (Quadro 01):

Quadro 1: Perguntas aplicadas aos bolsistas do PIBID

\begin{tabular}{|l|}
\hline PERGUNTAS \\
\hline 1.Durante os nossos encontros, discutimos sobre as Pesquisas em Educação Matemática. O \\
que você considerou mais importante para o aprendizado de matemática? Por quê? \\
\hline 2. Nesses encontros, em que também foram trabalhadas questões de leitura e escrita nas \\
propostas das oficinas, você julgou importante para o planejamento das atividades? \\
\hline 3. Como foram as aulas de matemática trabalhadas na ocasião das oficinas? Escreva um pouco \\
sobre as aulas (comente sobre o início, bem como sobre o desenvolvimento dos temas \\
propostos). \\
\hline $\begin{array}{l}\text { 4.Você considera que os encontros possam melhorar suas ações no processo de ensino- } \\
\text { aprendizagem de matemática? Quais aspectos foram melhorados? Em que você acha que pode } \\
\text { ter contribuído? }\end{array}$ \\
\hline
\end{tabular}

Fonte: Perguntas elaboradas pelo autor

Objetivei, com essas perguntas, saber do acadêmico em iniciação à docência como aplica seus conhecimentos em situações de vivências e práticas pedagógicas. Além disso, integrar o aluno em formação inicial ao campo profissional é oportunizar-lhe uma possibilidade de ampliar sua formação teórico/prática, bem como apresentar propostas ou sugestões para o aprimoramento das ações no uso da leitura e da comunicação nas aulas de matemática.

O portfólio é um material que reúne uma série de ações, que agregam valores ao processo de experiência desenvolvida ao longo do projeto. Procura-se formalizar múltiplos aspectos e dimensões do processo de ensino-aprendizagem, no sentido de aprofundar o conhecimento adquirido no desenvolvimento do projeto. E assim, com o aprofundamento das práticas didático-pedagógicas na dimensão profissional, estimular o desenvolvimento criativo. 
A orientação dada aos alunos da iniciação à docência para a elaboração de seus portfólios consistia nas sequências didáticas propostas nas atividades, dos recursos didáticos e das práticas comunicativas e leitoras.

As notas de campo consistiam no registro escrito dos diálogos estabelecidos na ocasião das reuniões do grupo. Esses registros representam um instrumento de coleta de produção de dados para a pesquisa qualitativa. Procedeu-se à gravação em vídeo de alguns diálogos, os quais posteriormente foram transcritos e analisados.

Os episódios de ensino consistiam em práticas educativas, realizadas por alunos do PIBID, na ocasião do desenvolvimento do projeto junto aos alunos da educação básica. Consistiam também em oficinas temáticas, nas quais foram gravados os momentos de interações e negociações de significados atribuídos à matemática. Com o auxílio de uma câmera de vídeo, esses episódios foram filmados e, posteriormente, transcritos e analisados.

A pesquisa qualitativa é a análise mais apropriada ao estudo por buscar o entendimento do fenômeno como um todo. Procedo a uma análise de dados na investigação qualitativa, pois ela emergiu como um planejamento construído estudando uma teoria, à medida que a pesquisa de campo foi ganhando uma autoevidência. Como nos afirma Godoy (1995, p.63), "quando um pesquisador de orientação qualitativa planeja desenvolver algum tipo de teoria sobre o que está estudando, constrói o quadro teórico aos poucos, à medida que coleta os dados e os examina". Essa situação reflete bem minha postura enquanto pesquisador e as reproduções dos dados investigados.

Para Bicudo (2006), a descrição é uma característica marcante nas pesquisas em Educação, e a pesquisa qualitativa é geralmente assumida. A abordagem qualitativa justifica-se em pesquisas na área da Educação Matemática; segundo Bicudo (2006), por suas concepções de atitudes que encontram na linguagem e no discurso seu uso para entendimento.

O presente estudo analisa as tarefas matemáticas oriundas da realização do projeto PIBID, com alunos do ensino fundamental e médio, em duas escolas públicas do município de Breves/PA. As análises também abordam a importância da valorização e aprimoramento dos futuros docentes em processo de formação, 
com o foco no potencial da comunicação, tornando o ato de comunicar uma atividade essencial para partilhar, participar, tornar algo comum, etc.

"A definição do objeto de pesquisa, assim como a opção metodológica, constitui um processo tão importante para o pesquisador quanto o texto que ele elabora ao final" (DUARTE, 2002, p.140). A pesquisa de campo pode ser vista como sinônimo da pesquisa qualitativa. Nesta acepção, as pesquisas de cunho qualitativo nos levam a orientação de esforços cuidadosos para a descoberta de novas informações (GODOY, 1995, p.58).

Para Demo (2002, p.351), "a qualidade acadêmica de qualquer proposta está, antes de tudo, na acuidade epistemológica, ou seja, na preocupação com a possibilidade do conhecimento e da captação da realidade". Dessas perspectivas, a qualidade acadêmica sobre os estudos aqui evidenciados está no trato do conhecimento matemático, como captação da realidade que emerge das práticas didático-pedagógicas no âmbito do PIBID. Nessa linha, a aprendizagem como ação, exige a consideração de um instrumento de investigação que faça referência a um conjunto de questões da realidade e, para isso, dialógico, hermenêutico, próprio da comunicação humana. Esse modo de ver, parte da definição de hermenêutica, que para Demo (2009, p. 249), "é a metodologia da interpretação que dirige-se a compreender formas e conteúdos da comunicação humana". Decorre desse fato, o interesse em fundamentar a importância da qualidade da comunicação nas aulas de matemática. Tendo como objetivo argumentar em favor desta possibilidade.

Procuro, assim, denominar esta pesquisa por perquirere, que é uma palavra oriunda do latim e significa buscar com cuidado, procurar por toda a parte, informar-se, inquirir, perguntar, indagar. Assim, defino minhas opções metodológicas, bem como o espaço para situar as pesquisas em Educação Matemática.

A partir daí, entra em cena a urgência de promover o processo lúdico, que permite a expressão e comunicação em diferentes situações que compõem o estudo da linguagem matemática, sem que com isso, se exclua uma forma de desprestigiar outros possíveis usos da linguagem, permeados por termos técnicos, metalinguísticos e formas abstratas de análise. 


\section{DANDO SENTIDO AS EXPERIÊNCIAS NO PIBID/MATEMÁTICA}

O depoimento dos alunos participantes, observado nas experiências práticas dos alunos em formação inicial quando inseridos no contexto educacional, confirma as dificuldades encontradas por aqueles que precisam vivenciar a escola e aprender práticas para lidarem no exercício futuro de suas profissões.

Podemos destacar esses momentos de vivências como uma possível via de enfrentar o ensino e a aprendizagem de matemática e de enriquecimento das ações dos alunos do PIBID. O estado de incerteza, sobretudo dos alunos da graduação, ao resolverem problemas nas aulas de matemática, levou-me a propor tarefas investigativas na Educação Básica, com o intuito de propiciar e incentivar o protagonismo dos estudantes em formação de licenciatura em matemática.

As relações estabelecidas no seio da relação didática contribuíram para o ensino-aprendizagem dos conceitos matemáticos uma vez que as 'falas' dos participantes do PIBID consistiram, também, como uma alternativa para promover um debate teórico e prático. No segundo ano do projeto PIBID realizamos atividades a partir dos pressupostos de que os alunos deveriam desenvolver os conhecimentos didáticos e matemáticos, por meio de recursos didáticos e materiais manipulativos.

Realizar atividades pedagógicas, tais como as tarefas já mencionadas, tornou as aulas dinâmicas e mais atraentes para os alunos. O material didático despertou outros interesses nos alunos participantes da educação básica. Fizemos, inclusive, a realização de uma feira de ciências e matemática no espaço escolar. Os alunos do ensino médio apresentaram aos visitantes, um simulador de um guindaste com o uso do software GeoGebra. O uso do software em matemática despertou o interesse para a comunicação das animações. A comunicação nas aulas e a capacidade de traduzi-los em animações, possibilitaram a reorganização das formas de apreensão e o acesso ao conhecimento matemático.

O uso de tecnologias está sendo cada vez mais vinculado à prática pedagógica. O software GeoGebra é uma ferramenta de apoio ao conhecimento matemático, pois, reúne recursos de geometria, álgebra e cálculo. Ferramentas 
tecnológicas, nas aulas de matemática, possibilitam novas práticas pedagógicas e novos ambientes de aprendizagens.

Outro dado importante revelado no presente estudo diz respeito à formação inicial dos alunos do PIBID, especificamente, sobre o período de formação inicial construída e o fato de vivenciarem-se como protagonistas em sala de aula ou como professores, fez, sem dúvida, com que compreendessem a importância da iniciação à docência na formação acadêmica. Conforme nos mostra no quadro 1 a transcrição do Aluno de iniciação à Docência (AD):

Quadro 1. Resposta do AD à Questão 4.

Questão 4. Você considera que os encontros possam melhorar suas ações no processo
de ensino-aprendizagem de matemática? Quais aspectos foram melhorados? Em que você
acha que pode ter contribuído?
Sim, os encontros têm sido extremamente importantes em minha formação. As discussões
em grupo sobre Educação Matemática nos possibilitaram trocar experiências vividas em
sala de aula, o que contribuiu para melhorar nossas ações enquanto professores de
matemática. Nesse sentido, tivemos a oportunidade de compartilhar nosso aprendizado e,
além disso, aprender com as experiências de outros colegas. Quanto aos aspectos
melhorados, os encontros contribuíram para despertar em mim o interesse por atividades
de pesquisa e a encarar as dificuldades de cada aluno de maneira diferente, levando em
consideração as peculiaridades individuais de cada um. Hoje, após estes quase dois anos
participando do projeto de iniciação à docência do PIBID, procuro ser mais cauteloso na
hora de comunicar-me com os alunos, pois sei que uma simples palavra colocada
inadequadamente durante a aula pode dificultar o entendimento dos conteúdos
matemáticos (AD).

Fonte: Arquivos da pesquisa

Uma das principais características evidenciadas na fala é o reconhecimento da importância das experiências e do estímulo dado aos sujeitos em formação inicial. Assumindo sua condição, a de quem precisa aperfeiçoar sua prática profissional, principalmente, a iniciativa de experenciar e aperfeiçoar a prática docente, uma vez que o projeto PIBID/matemática propõe, aos alunos em formação inicial, o desafio de conviver com a realidade da educação básica. Essa reconfiguração consiste em um movimento que deve incidir na formação docente e nos conhecimentos didáticos que vêm dos espaços onde participam. Ainda sobre as experiências do aluno (ver quadro 2 abaixo):

Quadro 2. Resposta do AD à Questão 1.

Questão 01. Durante os nossos encontros, discutimos sobre as Pesquisas em Educação Matemática. O que você considerou mais importante para o aprendizado de matemática? Por quê?

Os encontros foram muito importantes, pois me fizeram entender que para ensinar Matemática não basta apenas repassar os conteúdos para os alunos, como se o aprendizado ocorresse de maneira automática. Mais do que isso, durante as discussões e 


\begin{abstract}
atividades práticas desenvolvidas no projeto percebi que existem muitos fatores que, durante a aula, podem contribuir ou inibir o aprendizado dos conteúdos matemáticos. Entre estes fatores o que mais me chamou a atenção foi a abordagem da Matemática enquanto linguagem, principalmente, quanto aos significados que os alunos podem dar a um conteúdo matemático, que nem sempre condiz com o sentido que o professor deseja repassar, dependendo da comunicação que é estabelecida entre o professor e a classe, seja através da escrita ou do diálogo. Por este motivo é importante que o professor seja cauteloso na hora de expor um conceito ou até mesmo propor um problema matemático $(A D)$.
\end{abstract}

Fonte: Arquivos da pesquisa

Como vemos, a comunicação na formação inicial desse aluno fez surgir novos interesses e motivações ao longo desse projeto, com referência às práticas leitoras e comunicativas que podem contribuir para o diálogo. A comunicação é, então, uma relação específica que acolhe e encontra o seu destinador. A resposta de $A D$ mostra como é importante o cuidado no falar em sala de aula para que não haja confusões: "por este motivo é importante que o professor seja cauteloso na hora de expor um conceito ou até mesmo propor um problema matemático". No quadro de respostas às perguntas 1 e 4 , o aluno em formação inicial AD destaca a importância da linguagem matemática para o desenvolvimento de estratégias de ensino e aprendizagem. Como se vê, nas transcrições abaixo:

A abordagem da Matemática enquanto linguagem, principalmente, quanto aos significados que os alunos podem dar a um conteúdo matemático, que nem sempre condiz com o sentido que o professor deseja repassar (Resposta de AD à pergunta 1).

Procuro ser mais cauteloso na hora de comunicar-me com os alunos, pois sei que uma simples palavra colocada inadequadamente durante a aula pode dificultar o entendimento dos conteúdos matemáticos (Resposta de AD à pergunta 4).

A falta de conhecimento de um termo pode deixar o aluno sem ação diante do texto matemático. Em função disso, a preocupação com a linguagem e comunicação nas aulas de matemática, pode possibilitar meios para melhorar a aprendizagem dos alunos, bem como favorecer o crescimento e desenvolvimento pessoal e docente.

A formação se refere, também, ao acesso a recursos e ao uso da tecnologia da informação e comunicação (TIC). Além disso, a formação matemática, nas abordagens pedagógicas que compõem a comunicação oral, situa as tarefas matemáticas a importância da linguagem enquanto ação. Essas características introduzem, no ensino, as capacidades de inovação e investigação pedagógica, 
indicando que tarefas matemáticas precisam ser implementadas nas experiências do fazer. Os novos professores devem ser preparados para o exercício da docência, na qual a teoria é aplicada à prática. Conforme mostro no quadro 3 abaixo:

Quadro 3. Resposta do AD à Questão 2.

Questão 2. Nesses encontros, em que também foram trabalhadas questões de leitura e escrita nas propostas das oficinas, o que você julgou importante para o planejamento das atividades? Justifique com exemplos.

Considerei importante para o planejamento das atividades, entre outros elementos, a leitura do referencial teórico, pois aprofundando o conhecimento literário acerca dos temas propostos, podemos traçar um caminho mais seguro das atividades a desenvolver nas aulas. Como exemplo, a leitura de artigos, dissertações e teses sobre o uso de tecnologias informáticas nas aulas de matemática, nortearam minhas ações no desenvolvimento das oficinas que serviram de pesquisa, as quais deram origem ao meu trabalho de conclusão de curso (AD).

Fonte: Arquivos da pesquisa

É preciso, ainda, saber interligar a teoria à prática para que alunos em formação vivenciem situações e estabeleçam conexões entre estes saberes. Essas conexões fazem parte do cotidiano do aluno que partilha e constitui um elemento norteador para o desenvolvimento de suas tarefas. Uma formação que articula prática e teoria visa formar o indivíduo em sua organização para um ensino que se oriente na perspectiva da ação: "Considerei importante para o planejamento das atividades, entre outros elementos, a leitura do referencial teórico, pois, aprofundando o conhecimento literário acerca dos temas propostos podemos traçar um caminho mais seguro das atividades a desenvolver nas aulas" (AD). Propiciar contextos de formação profissional nos quais a experiência investigativa é apontada na formação acadêmico-científico cria e reforça no âmbito do PIBID uma educação cientifica.

Considerando o estudo de Garnica (1997) acerca do que deve ser pensado para formação do professor de matemática, sistematizamos os seguintes pontos:

1) Articulação entre a escola e Universidade;

2) Dicotomia entre conhecimento especifico/pedagógico;

3) Incorporação dos elementos da pesquisa, devendo ser incluídas iniciações cientificas na formação do futuro professor;

4) Ministrar o conteúdo por metodologias alternativas. 
Observamos nesses parâmetros pelo qual preconiza Garnica (1997) elementos do programa de incentivo à docência (PIBID). Destacamos ainda, na constituição identitária do professor de matemática em formação a tensão entre a teoria e prática.

É hoje consensual, a dicotomia existente entre o conhecimento específico e conhecimento pedagógico, em que ocupa boa parte da discussão entre pesquisadores.

Em nossas análises, entendemos que os aspectos que acentuam a relação do conhecimento didático e matemático é de natureza do saber "do que" e o "como ensinar". A relação é organizada em forma de mensagens que apresentam a necessidade do texto sua abordagem por meio da pesquisa, cujos conceitos têm peso importante nas práticas leitoras e comunicativas em aulas de matemática. Os limites estão na dicotomia existente entre os domínios pedagógico e específico. É nessa relação conflituosa que se funda a atuação comunicativa da ação, como sendo o investimento qualitativo na prática leitora que é de caráter projetivo, tal como a tarefa matemática de ser diretiva ou de condução.

Há, evidentemente, a presença de uma nova interface no texto, pois, observamos instrumentos variados para a comunicação. Quer dizer, percebemos o som, o gesto e os sentimentos que vestem o corpo para as caminhadas, como o culto ao significado de que é o conhecimento na ação. Dito de forma mais abrangente, Schön (1995) descreve o conhecimento profissional como conhecimento na ação, e explicita a esses como: reflexão na ação (ocorre simultaneamente à prática) e reflexão sobre a ação (ocorrendo após a ação). Nessa perspectiva, Schön propõe uma nova epistemologia da ação, em que não se pode ensinar aquilo que é necessário o estudante saber.

Vejamos algumas respostas dadas pelos alunos da educação básica ao questionário proposto e aplicado por AD. 
Figura 1. Resposta dos alunos (A) sobre a importância do uso de tecnologias nas aulas de matemática.

5. Você considera importante o uso de tecnologias nas aulas de Matemática? Por qu $X \operatorname{sim} \square$ Não

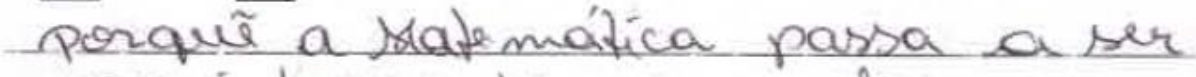
mas interressante nas aulas

5. Você considera importante o uso de tecnologias nas aulas de Matemática? Por quê?

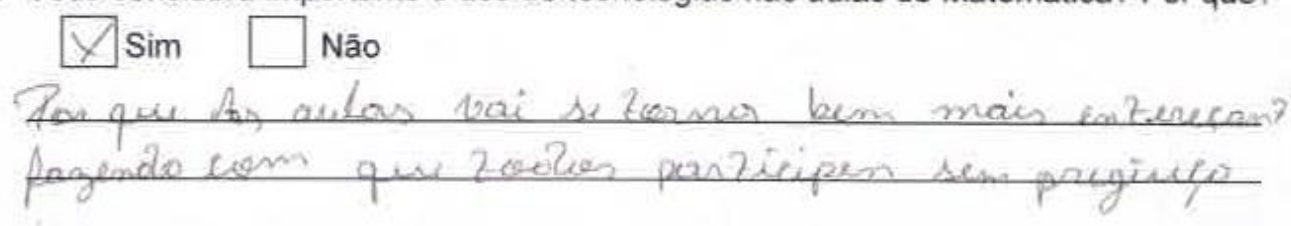

5. Você considera importante o uso de tecnologias nas aulas de Matemática? Por quê?

X $\operatorname{sim} \square$ Não

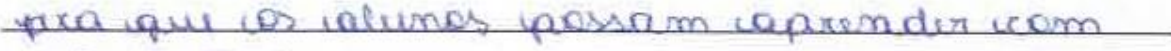

mois intusias me

5. Você considera importante o uso de tecnologias nas aulas de Matemática? Por quê?

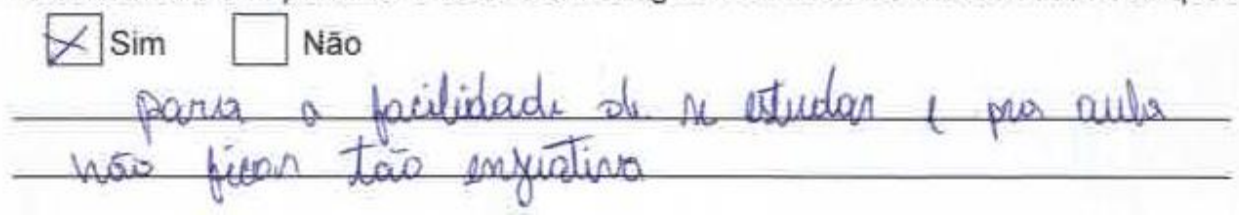

Fonte: Arquivo da pesquisa

Como visto, a introdução das ferramentas tecnológicas no ensino possibilita aos participantes não somente compreender a realidade em que vivem, visa, também, a provocar transformações no enfrentar os desafios das práticas de ensino e como aprendem. Fica evidente, nas respostas, que a formação de profissionais para o campo da educação necessita de apoio e de incentivo para que favoreça a ampliação teórico-prática. O projeto do PIBID pode contribuir para que esses futuros professores construam práticas qualificadas às tarefas matemáticas e o atentem ao cuidado que o professor deve tomar na hora de sequenciar a tarefa matemática.

Dentre os exemplos fornecidos, incluo os estudos do aluno da iniciação à docência $(A D)$, procurando compreender as posturas e diretrizes didáticopedagógicas do trabalho do jovem professor em formação inicial. 
Quadro 4. Resposta do $A D_{1}$ à Questão 4.

Questão 4. Você considera que os encontros possam melhorar suas ações no processo
de ensino-aprendizagem de matemática? Quais aspectos foram melhorados? Em que você
acha que pode ter contribuído?
Sim, os encontros têm sido extremamente importantes em minha formação. As discussões
em grupo sobre Educação Matemática nos possibilitaram trocar experiências vividas em
sala de aula, o que contribuiu para melhorar nossas ações enquanto professores de
matemática. Nesse sentido, tivemos a oportunidade de compartilhar nosso aprendizado e,
além disso, aprender com as experiências de outros colegas. Quanto aos aspectos
melhorados, os encontros contribuíram para despertar em mim o interesse por atividades
de pesquisa e a encarar as dificuldades de cada aluno de maneira diferente, levando em
consideração as peculiaridades individuais de cada um. Hoje, após estes quase dois anos
participando do projeto de iniciação à docência do PIBID, procuro ser mais cauteloso na
hora de comunicar-me com os alunos, pois sei que uma simples palavra colocada
inadequadamente durante a aula pode dificultar o entendimento dos conteúdos
matemáticos.

Fonte: Arquivo da pesquisa

Uma das principais características evidenciadas na fala é o reconhecimento da importância das experiências e do estímulo dado aos sujeitos em formação inicial. Assumindo sua condição, a de quem precisa aperfeiçoar sua prática profissional, principalmente, a iniciativa de experenciar e aperfeiçoar a prática docente, uma vez que o projeto PIBID/matemática propõe, aos alunos em formação inicial, o desafio de conviver com a realidade da Educação Básica. Segundo Perez (2005, p.252) "a reflexão é vista como um processo em que o professor analisa sua prática, compila dados, descreve situações, elabora teorias, implementa e avalia projetos e partilha suas ideias com colegas e alunos". Essa reconfiguração consiste em um movimento que deve incidir na formação docente e nos conhecimentos didáticos que vêm dos espaços onde participam.

\section{APONTAMENTOS SOBRE AS ANÁLISES}

Em síntese, o PIBID influenciou positivamente na formação inicial dos licenciandos, já que fez eclodir de modo sistemático sobre suas práticas comunicativas, a interação e a discussão com seus colegas sobre o trabalho docente e, sobretudo, por utilizarem de aspectos teóricos e práticos para compreenderem e aprimorarem sua experiência no ambiente escolar, no envolvimento com os alunos do ensino fundamental e médio, antes mesmo de se formarem.

Diante do exposto, há necessidade de investir em tarefas matemáticas que explorem a comunicação nas aulas de matemática com o uso de tecnologias. De modo geral, a constituição de tarefas que explorem o uso da comunicação se 
constitui em um grande desafio para o professor que ensina matemática, sobretudo, quais recursos devam apoiar para o desenvolvimento das aulas? Que relação estabelecer nas interações comunicativas envolvendo professor, aluno e o saber matemático? Desdobram-se ainda, outras questões: que contribuição para um melhor conhecimento do professor corresponde às práticas de investigações? O dialogo lança luz sobre práticas de formação colaborativa. Cabe destacar, outra questão: o que permite aos professores em formação inicial a emersão de desafios nas tarefas matemáticas, na colaboração como possibilidade de ressignificação de criações de práticas inovadoras? Sendo assim, a formação do professor deverá constituir novos domínios de ação sobre a prática pedagógica e a colaboração entre profissionais que já exercem a docência e os jovens/futuros professores em processo de formação inicial. 


\section{REFERÊNCIAS}

ALRØ, H; SKOVSMOSE, O. Diálogo e Aprendizagem em Educação Matemática. Trad. Orlando de A. Figueiredo. Belo Horizonte: Autêntica, 2006. 160 p.

BICUDO, M. A. V. Pesquisa Qualitativa e Pesquisa Qualitativa segundo a abordagem fenomenológica. In: BORBA, M. C; ARAÚJJ, J. L. (Orgs.). Pesquisa Qualitativa em Educação Matemática. Belo Horizonte: Autêntica, p. 101-114, 2006.

DEMO, P. Cuidado metodológico: signo crucial da qualidade. Sociedade e estado, v. 17, n. 2, p. 349-373, 2002.

2009.

Metodologia Científica em Ciências Sociais. 3 ed. São Paulo: Atlas,

DEWEY, J. Cómo pensamos: la relación entre pensamento reflexivo y processo educativo. Traducción de Marco Aurelio Galmarini. Barcelona: Paidós, 2010.

DUARTE, R. Pesquisa qualitativa: reflexões sobre o trabalho de campo. Cadernos de pesquisa, v. 115, n. 1, p. 139-54, 2002.

FIORENTINI, D. \& SOUZA e MELO, G. F. Saberes docentes: Um desafio para acadêmicos e práticos In: GERALDI, C. (org). Cartografias do trabalho docente: Professor(a)- pesquisador(a). Campinas: Mercado das Letras, ALB, 2003.

GARNICA, A. V. M. Professor e professor de matemática: das informações que se tem acerca da formação que se espera. Revista da Faculdade de Educação, v. 23, n. 1-2, 1997a.

GODOY, A. S. Pesquisa qualitativa: tipos fundamentais. Revista de Administração de empresas, v. 35, n. 3, p. 20-29, 1995.

LIBÂNEO, J. C. Adeus professor, adeus professora?: novas exigências educacionais e profissão docente. São Paulo: Cortez Editora, 2011.

MENEZES, L; PONTE, J. P. Investigação colaborativa de professores e ensino da Matemática: caminhos para o desenvolvimento profissional. Jornal Internacional de Estudos em Educação Matemática, 2009. Disponível em: https://core.ac.uk/download/pdf/12423839.pdf

NÓVOA, A. (Org.). Vidas de Professores. Porto: Porto Editora, 1992.

PEREZ, G. Prática reflexiva do professor de matemática. In: BICUDO, Maria AP. V., BORBA, Marcelo C. (org.). Educação Matemática: pesquisa em movimento. São Paulo: Cortez Editora, p. 250-263, 2005.

SCHON, D.A. Formar professores como profissionais reflexivos. In: NÓVOA, A. Os professores e a sua formação. 2 ed. Lisboa: Dom Quixote, 1995, p.77-92. 